\title{
Epidemiology and Treatment of Patients with Rheumatoid Arthritis, Psoriatic Arthritis and Psoriasis in Germany: A Real-World Evidence Study
}

\author{
Claudia Grellmann • Wojciech Dombrowsky • Volker Fabricius • \\ Robert Suruki · Anna Sheahan · Lars Joeres
}

Received: August 14, 2020 / Accepted: September 30, 2020 / Published online: October 30, 2020

(C) The Author(s) 2020

\begin{abstract}
Introduction: Rheumatoid arthritis (RA), psoriatic arthritis (PsA) and psoriasis (PSO) are chronic inflammatory diseases that have a substantial impact on patients' health. This retrospective database study aimed to assess the epidemiology, comorbidities, diagnosis and treatment patterns of RA, PsA and PSO in the German population.

Methods: Data were extracted from the Deutsche Forschungsdatenbank für Abrechnungsinformationen der Krankenversicherung database from 2012 to 2016 for patients aged $\geq 18$ years holding full health coverage in the reporting year at least. Diagnoses were defined according to International Classification of Diseases (ICD)-10 codes. Reported outcomes included prevalence and incidence rates, pre-defined comorbidities, diagnosing and
\end{abstract}

Electronic Supplementary Material The online version of this article (https://doi.org/10.1007/s12325020-01522-8) contains supplementary material, which is available to authorized users.

C. Grellmann ( $₫)$

Gesundheitsforen Leipzig GmbH, Leipzig, Germany

e-mail: grellmann@gesundheitsforen.net

W. Dombrowsky · V. Fabricius · L. Joeres

UCB Pharma, Monheim am Rhein, Germany

R. Suruki $\cdot$ A. Sheahan

UCB Pharma, Raleigh, NC, USA treating physicians, and treatment exposure. A subgroup analysis was performed for women of childbearing age (females aged 18-45 years).

Results: The prevalence rates of RA, PsA and PSO in Germany were consistent over the study period; by 2016 they were $0.4 \%, 0.3 \%$ and $2.1 \%$, respectively, and in women of childbearing age they were $0.2 \%, 0.2 \%$ and $1.5 \%$, respectively. RA, PsA and PSO were predominantly observed among patients aged $>45$ years. RA and PsA were more prevalent in women, while PSO had an approximately equal gender distribution. Depressive episodes were the most frequently reported comorbidity in 2016 (RA: 25.7\%; PsA: 25.1\%; PSO: $17.8 \%$ ), and this was similar in women of childbearing age (RA: 20.5\%; PsA: 23.4\%; PSO: $16.3 \%$ ). Approximately $50 \%$ of patients with RA and PsA and $6 \%$ of patients with PSO were receiving systemic treatment in 2016, of which methotrexate (RA: 38.4\%; PsA: 30.2\%; PSO: $2.2 \%$ ) was most common. Biologic therapies were the least frequently used treatment options (RA: 28.9\%; PsA: 20.9\%; PSO: $1.8 \%)$.

Conclusions: This analysis provides key epidemiological information for patients with RA, PsA and PSO, including in women of childbearing age, in Germany and highlights common comorbidities and that patients were likely receiving insufficient treatment for these diagnoses. 
Keywords: Anti-TNF; German population; Psoriasis; Psoriatic arthritis; Rheumatoid arthritis

\section{Key Summary Points}

Why carry out this study?

Rheumatoid arthritis (RA), psoriatic arthritis (PsA) and psoriasis (PSO) are chronic inflammatory diseases that have a substantial impact on patients' health and quality of life.

Real-world data can provide insights into the prevalence and treatment of these diseases in heterogeneous patient populations, yet there are limited realworld studies available for RA, PsA and PSO in the German population.

This study aimed to assess the epidemiology, comorbidities, diagnosis and treatment patterns of RA, PsA and PSO in the German population.

\section{What was learned from the study?}

This study describes the epidemiology and treatment patterns of RA, PsA and PSO in Germany and highlights that many patients were likely undertreated for their diagnoses.

Depression was a frequently reported comorbidity for RA, PsA and PSO patients, emphasising the mental burden experienced by these patients.

\section{DIGITAL FEATURES}

This article is published with digital features, including a summary slide, to facilitate understanding of the article. To view digital features for this article go to https://doi.org/10.6084/ m9.figshare.13006355. 
insufficient disease management [2, 12]. For patients with PSO, phototherapy and fumaric acid esters are often effective first-line therapies, although they do not improve the symptoms of concomitant PsA [13], and MTX, cyclosporin and acitretin are approved systemic treatment options [14]. Patients with severe PSO and patients with both PsA and PSO are often prescribed bDMARDs, but loss of efficacy following treatment with the first bDMARD is common amongst these patients [2]. The wide variety of treatment options available for RA, PsA and PSO may result in differing treatment patterns within patient groups.

Real-world data are particularly useful to provide insights into the prevalence and treatment of diseases in heterogeneous patient populations beyond that obtained from randomised controlled trials $[15,16]$. At present, there are limited reports from real-world studies available for RA [17], PsA [3, 18] and PSO [18-22]; in particular, real-world studies are scarce for the German population. This retrospective database study aimed to assess the epidemiology, comorbidities, diagnosis and treatment patterns of RA, PsA and PSO in the German population.

\section{METHODS}

\section{Patients and Study Design}

This retrospective population-based study used data from a German healthcare insurance database (Deutsche Forschungsdatenbank für Abrechnungsinformationen der Krankenversicherung; Vilua Healthcare $\mathrm{GmbH}$ ), reporting data from 2012 to 2016 (Fig. 1). The database analyses carried out in this study were performed by Data Scientists at Vilua Healthcare $\mathrm{GmbH}$ via encrypted remote access.

The study design used two different methods for reporting the different outcomes. Crosssectional analyses were performed within each calendar year for prevalence, incidence, patient demographics, treatment distribution, comorbidities and diagnosing physicians (Fig. 1). Retrospective patient cohorts were identified for analysis of treatment persistence, dosing patterns, treating physicians, treatment exposure and treatment lines. The index date for the retrospective cohort analyses was defined differently depending on the outcome analysed and could be at any time point during the study period (Fig. 1). Only adult patients $\geq 18$ years of age were included. Patients with a diagnosis (defined as a reliable outpatient diagnosis or an inpatient diagnosis per year) of RA, PsA or PSO according to the defined International Classification of Diseases (ICD)-10 codes at any time point during the study were included (RA: M05.8, M06.0, M06.8; PsA: M07.0, M07.1, M07.2, M07.3, L40.5; PSO: L40.0, L40.8, L40.9). The PsA subgroup included patients who were diagnosed with PsA only or with PSO plus PsA. For each indication, a subgroup analysis for women of childbearing age (i.e. female patients aged $18-45$ years) was performed. Patients who died during the study period were not excluded from the analysis.

Ethical approval was not required for this study as the data analysed were retrospective and were pseudonymised and anonymised, so that the subsequent assignment to patient data was impossible. Permission to use the database was provided by Arvato Health Analytics, the former operators of the database.

\section{Epidemiology}

Annual cross-sectional prevalence rates for each indication were calculated by dividing the number of diagnosed RA, PsA and PSO patients in the database (defined as a reliable outpatient diagnosis or an inpatient diagnosis by the defined ICD-10 codes) by the total number of patients with full health coverage in the reporting year (Fig. 1). Prevalence data were then extrapolated to the German population using different extrapolation factors for each year. Extrapolation factors were calculated as the ratio of the number of insured persons of statutory health insurances in Germany and the number of insured persons with full health cover in the database in each year. Annual cross-sectional incidence rates (2013-2016) were calculated for patients who did not have a diagnosis of RA, PsA or PSO for one calendar 


\section{Cross-sectional analyses within each calendar year}

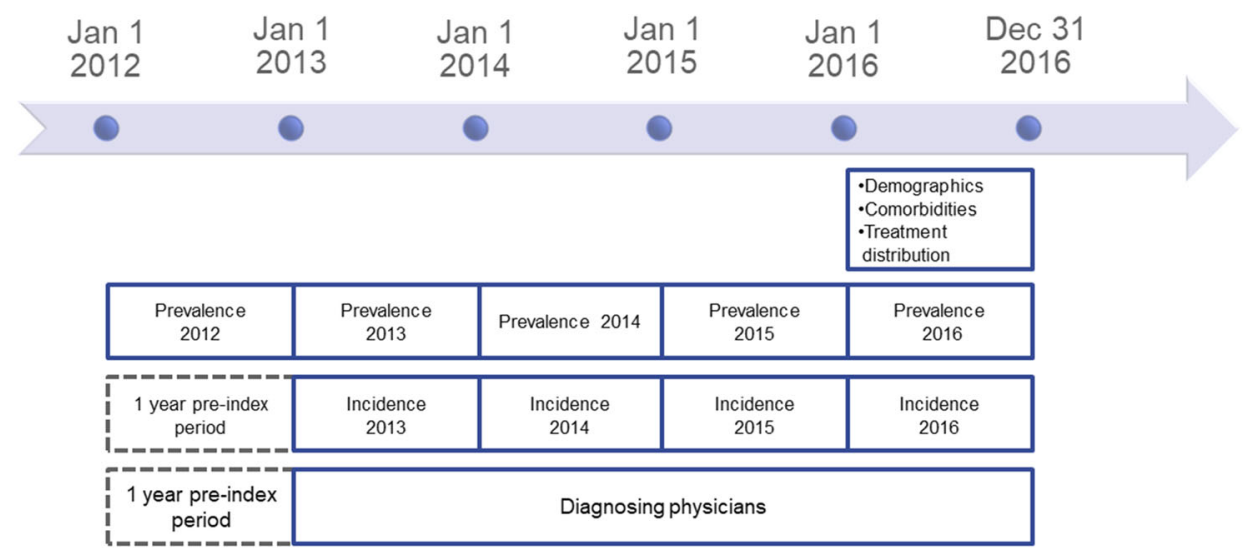

\section{Retrospective cohort analyses}
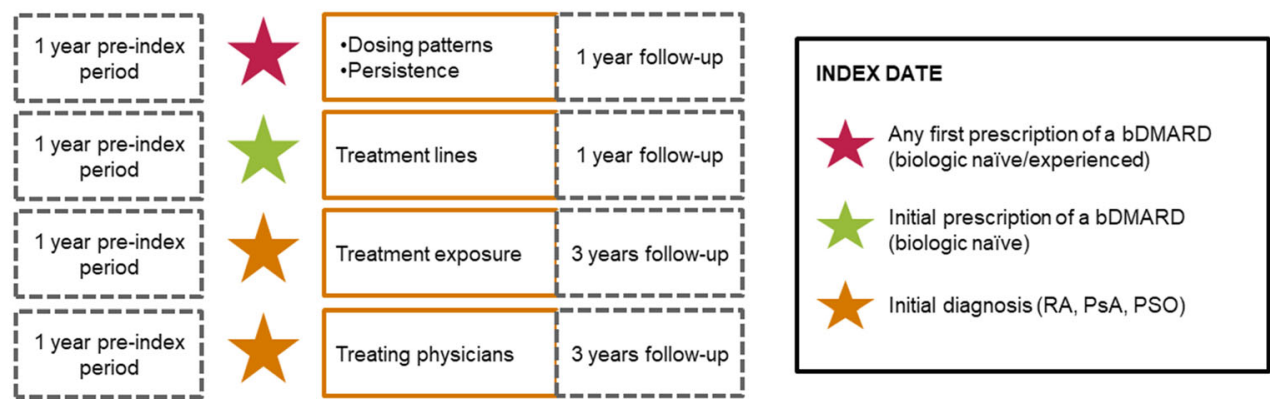

Fig. 1 Study design. Cross-sectional analyses were performed within each calendar year. The index date for the retrospective cohort analyses could be at any time point during the study period. $D D M A R D$ biologic diseasemodifying anti-rheumatic drug, $P S A$ psoriatic arthritis, PSO psoriasis, $R A$ rheumatoid arthritis year prior to initial diagnosis and who held full health coverage in both the reporting year and the preceding year (Fig. 1). Comorbidities were identified from a pre-defined list (Table S1) and the frequency of each comorbidity was reported for each indication in 2016 only (cross-sectional analysis; Fig. 1). Comorbidities were possible before, simultaneously or after RA, PsA or PSO diagnosis in the reporting year.

\section{Diagnosing Physicians, Treating Physicians, Treatment Exposure and Persistence}

The specialisations of physicians responsible for the initial diagnoses of RA, PsA or PSO were analysed annually between 2013 and 2016 (cross-sectional analysis with a pre-index period of one calendar year; Fig. 1). Information on the speciality of physicians was only available for a subsample (approximately 80\%) of patients in the database and so data are only presented for these patients. Due to information on outpatient diagnosis being available quarterly, patients might by assigned to multiple physicians; in these cases mixed groups of physician specialities are used.

The specialisations of physicians prescribing each class of treatment were analysed for each indication (retrospective cohort analysis for patients without a diagnosis for one calendar year prior to the index date [in this case the initial diagnosis of RA, PsA or PSO] and maximum three years of follow-up; Fig. 1). The proportion of patients prescribed the following pre- 
defined treatment classes were reported along with associated treatment exposures: anti-TNF biologics (RA: adalimumab, certolizumab pegol, etanercept, infliximab, and golimumab; PsA: adalimumab, certolizumab pegol, etanercept, infliximab and golimumab; PSO: adalimumab, etanercept and infliximab), other biologics/ small molecules (RA: abatacept, rituximab and tocilizumab; PsA: apremilast and ustekinumab; PSO: apremilast, secukinumab and ustekinumab), other immunosuppressants (RA: leflunomide, MTX and sulfasalazine; PsA: acitretin, ciclosporin, fumaric acid, leflunomide, MTX and sulfasalazine; PSO: acitretin, ciclosporin, fumaric acid and MTX) for the time period stated. Patients were without a diagnosis of RA, PsA or PSO for one calendar year prior to the index date and must have held full health coverage for the pre-index year and for three years of follow-up (retrospective cohort analysis; Fig. 1).

The distribution of systemic anti-inflammatory medication was analysed for prevalent RA, PsA and PSO patients holding full health coverage in 2016 (cross-sectional analysis; Fig. 1). The proportion for each medication was calculated as the ratio between the number of patients being treated with a specific medication and the total number of patients in the database, for each indication. Biologic switching (including those used as monotherapy or with csDMARDs) was analysed for biologicnaïve patients (defined as patients without biologic treatment for at least one year prior to the index date [in this case the initial prescription of a bDMARD]) holding full health coverage and with at least one year of follow-up in a retrospective cohort analysis (Fig. 1).

Dosing patterns were only analysed for PSO patients receiving biologic treatment as PSO has a more flexible dosing recommendation per label. For example, the maintenance dose of certolizumab pegol for adult patients with PSO is $200 \mathrm{mg}$ every two weeks (Q2W), which can be increased to $400 \mathrm{mg}$ Q2W in patients with insufficient response. High-level dosing was defined as $\geq 170 \%$ or $\geq 200 \%$ of a single labelrecommended dose and was required for a period of at least 30 days; patients receiving $\geq 170 \%$ of a single label-recommended dose for $<30$ days were assigned to the single labelrecommended dosing group. Patients were required to be without a bDMARD prescription for one calendar year prior to the index date (in this case any first prescription of a bDMARD for biologic-naïve or experienced patients) and one year of follow-up (retrospective cohort analysis; Fig. 1).

Persistence on treatment was analysed for patients with a diagnosis of RA, PsA or PSO and with a bDMARD prescription for one calendar year prior to the index date (in this case any first prescription of a bDMARD for biologic-naïve or experienced patients) and one year of follow-up with full health coverage (retrospective cohort analysis; Figure S1b). The total treatment duration may include gaps of $\leq 60$ days; however, gaps of $>60$ days were defined as therapy breaks. Patients were observed from the initial prescription until either therapy break or the end of the observation period.

\section{Statistical Analysis}

Patient populations, prevalence and incidence rates are reported as ranges (minimum to maximum) for the study period. Prevalence and incidence rates were calculated using extrapolated numbers from the total database populations to account for patients with statutory health insurances in Germany. For the pre-defined list of comorbidities, diagnosing physicians, treating physicians, treatment distribution (including treatment lines) and dosing patterns, the proportion of patients in percent is reported. Subgroup analyses are presented for women of childbearing age (female patients aged 18-45 years) for disease prevalence, incidence rates, comorbidities and treatment distribution. Persistence on treatment and average treatment durations were analysed using Kaplan-Meier methods, which included censored patients to the end of the observation period. Since patients were required to have full health cover in the observation period, no missing data would be expected. 


\section{RESULTS}

\section{Database and Patient Characteristics}

The total number of insured patients included in the database between 2012 and 2016 ranged from 965,759 to $1,909,411$ for RA and from 971,910 to 1,930,158 for PsA and PSO. The total number of women of childbearing age ranged from 244,479 to 425,589 patients (RA) and 244,492 to 425,769 patients (PsA/PSO).

Extrapolated populations from the total database population, calculated to account for patients with statutory health insurances in Germany, ranged in size from 257,790 to 327,870 for RA patients (women of childbearing age: 20,160 to 26,875 ; Table S2), from 155,323 to 191,256 for PsA patients (women of childbearing age: 16,859 to 19,419 ; Table S2) and from $1,245,985$ to $1,380,933$ for PSO patients (women of childbearing age: 179,790 to 184,088; Table S2).

The demographics of patients with RA revealed a predominance of patients aged 45-79 years, with more women affected than men (Fig. 2a). PsA was most common in patients aged 45-64 years, and women were predominantly affected (Fig. 2b). The gender distribution was closer to equal in patients with PSO, but with a similar peak of prevalence among patients aged $45-79$ years (Fig. 2c).

\section{Epidemiology}

\section{Prevalence}

The overall prevalence rates (minimum-maximum) during the study period (2012-2016) were $0.4-0.5 \%$ for RA and $2.1-2.3 \%$ for PSO. The prevalence rates for PsA were $0.3 \%$ in any given year during the study period (Fig. S1a; Table S3). Prevalence rates during the study period amongst women of childbearing age were $0.2 \%$ for RA, between $0.1-0.2 \%$ for PsA and $1.5 \%$ for PSO (Fig. S1b; Table S3). Prevalence rates for all indications remained relatively constant during the study period (Fig. S1a, b; Table S3).
Fig. 2 Patient demographics for prevalent patients by age and gender group (extrapolated data from 2016). a RA patients $(n=3927)$. b PsA patients $(n=2877)$. c PSO patients $(n=20,240)$. Ps $A$ psoriatic arthritis, PSO psoriasis, $R A$ rheumatoid arthritis

\section{Incidence Rates}

Incidence rates for RA, PsA and PSO remained constant between 2013 and 2016 (Fig. S1c, d). Incidence rates of RA were $0.1-0.2 \%$ for the overall population and $0.1 \%$ among women of childbearing age (Fig. S1c, d). The incidence of PsA was $0.1 \%$ throughout the study period, across the overall population and the women of childbearing age subgroup (Fig. S1c, d). Incidence rates of PSO were between 0.6 and $0.7 \%$ for the overall population (Fig. S1c) and $0.5-0.6 \%$ among women of childbearing age, throughout the study period (Fig. S1d).

\section{Comorbidities}

In 2016, depressive episode (ICD-10: F32) was the most frequently reported pre-defined comorbidity across all indications (RA: 25.7\%; PsA: 25.1\%; PSO: 17.8\%; Fig. 3a-c). These observations were similar among women of childbearing age (RA: 20.5\%; PsA: 23.4\%; PSO: 16.3\%; Fig. 3a-c). Pre-defined comorbidities for RA patients remained largely consistent over the reporting period (2012-2016), although there was an increasing trend in rates of recurrent depressive disorder (ICD-10: F33; 2012: 7.2\% of patients; $2016: 10.1 \%$ of patients). In the overall PsA and PSO patient populations, recurrent depressive disorder was also a common comorbidity (PsA: 10.3\%; PSO: 6.5\%; Fig. 3a-c).

Cardiovascular comorbidities were also common across all indications, including atherosclerosis (ICD-10: I70; RA: 8.3\%; PsA: 5.5\%; PSO: $5.2 \%$ ), thromboembolism (ICD-10: I26, I80, I82, T80.0, T81.7, T82.8; RA: 4.6\%; PsA: 5.7\%; PSO: $4.6 \%$ ) and congestive heart disease (ICD-10: I50; RA: 7.2\%; PsA: 4.7\%; PSO: 4.6\%). The presence of cardiovascular comorbidities is likely age-related and accordingly these were 

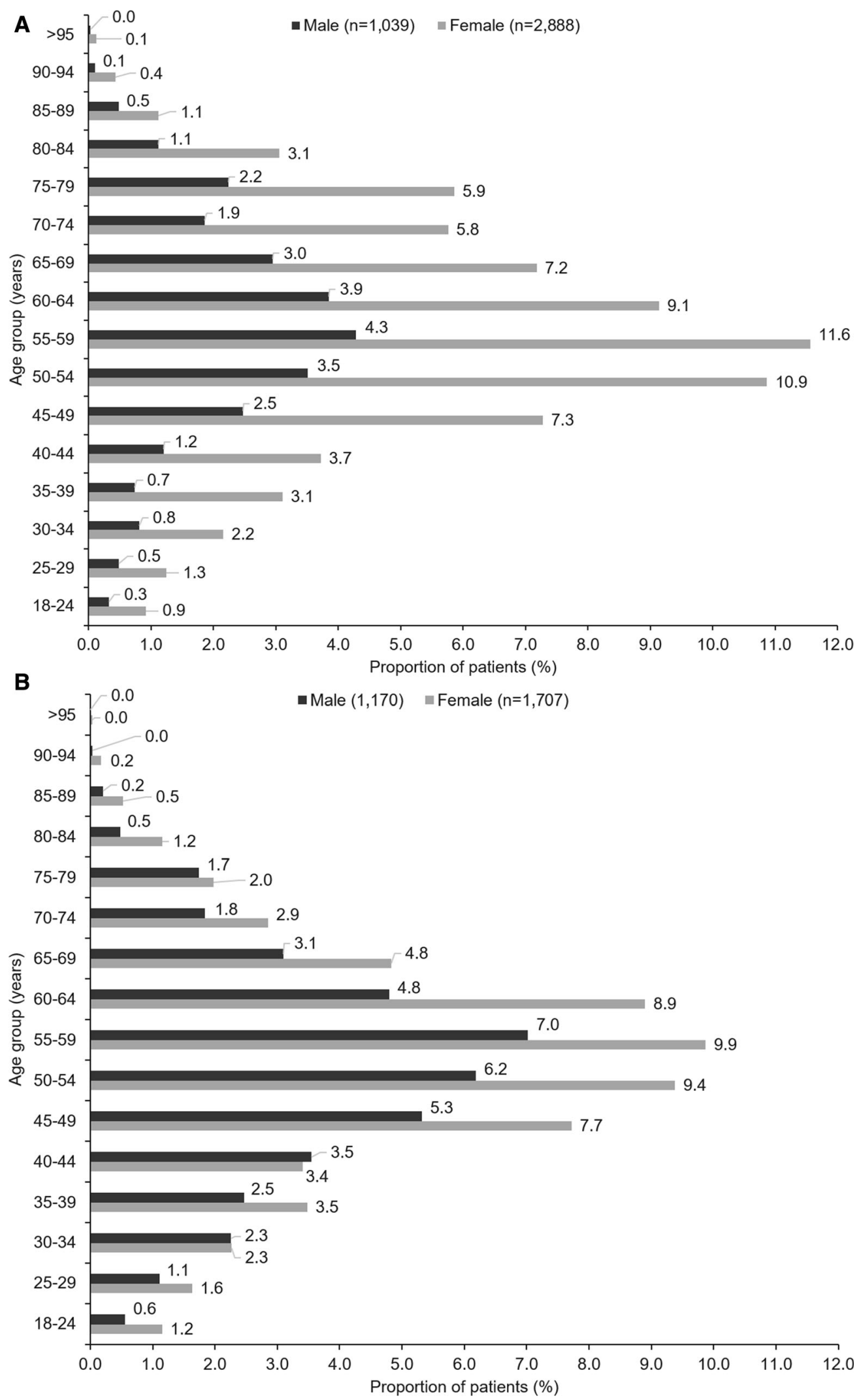


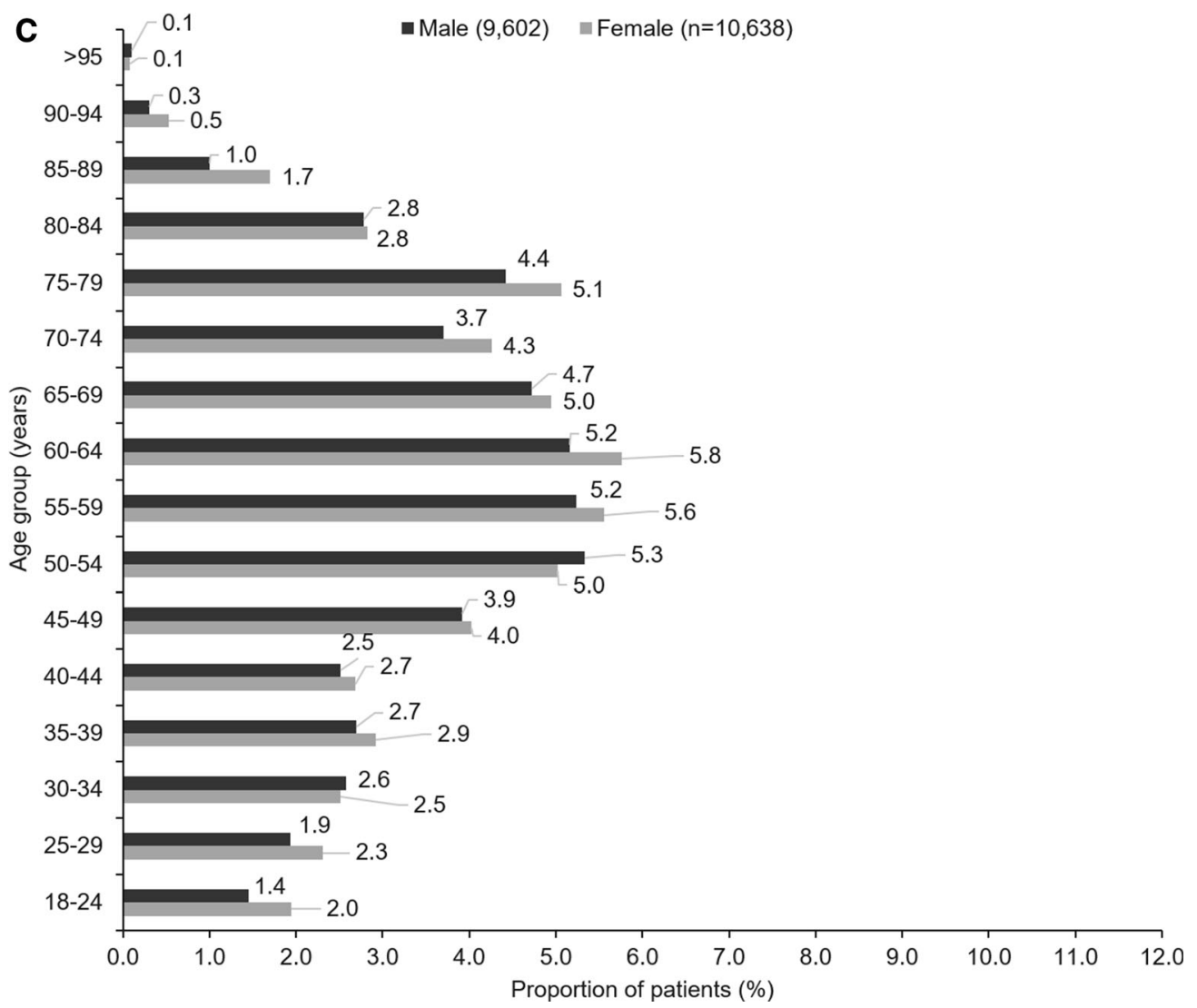

Fig. 2 continued

reported less frequently among the younger women of childbearing age population.

Osteoporosis (ICD-10: M80, M81) affected $20.4 \%$ of the overall RA patient population in $2016(n=802)$ and was reported much less frequently among women of childbearing age with RA $(4.7 \% ; n=23)$, who were on average younger than the overall RA population (Fig. 3a). PsA and PSO were common comorbidities among women of childbearing age with RA $(7.4 \%$ and $8.2 \%$ of patients, respectively, Fig. 3a).

\section{Diagnosing and Treating Physicians}

\section{Diagnosing Physicians}

Approximately one third of patients (29.1-35.6\%) were diagnosed with RA by hospital physicians and a further quarter (25.8-29.9\%) were diagnosed by rheumatologists (Fig. 4a). In contrast, PsA was diagnosed by a broader range of physicians, including dermatologists, rheumatologists, general medicine specialists and internal medicine specialists (Fig. 4b). The majority of patients with PSO were diagnosed by dermatologists (58.3-59.5\%) with around one quarter diagnosed by general medicine specialists (24.1-27.0\%; Fig. 4c). These observations were relatively consistent from 2012 to 2016 across all indications.

\section{Treating Physicians}

For patients with RA, anti-TNF therapies and immunosuppressants were most frequently prescribed by rheumatologists $(64.7 \%$ and 56.9\%, respectively; Fig. 5a). Approximately a quarter of patients $(24.0 \%)$ with PsA were prescribed immunosuppressants by dermatologists and a further $27.3 \%$ by rheumatologists (Fig. 5b). Patients with PSO were predominantly 
A

- Overall $(n=4,530) \quad$ Women of childbearing age $(n=340)$

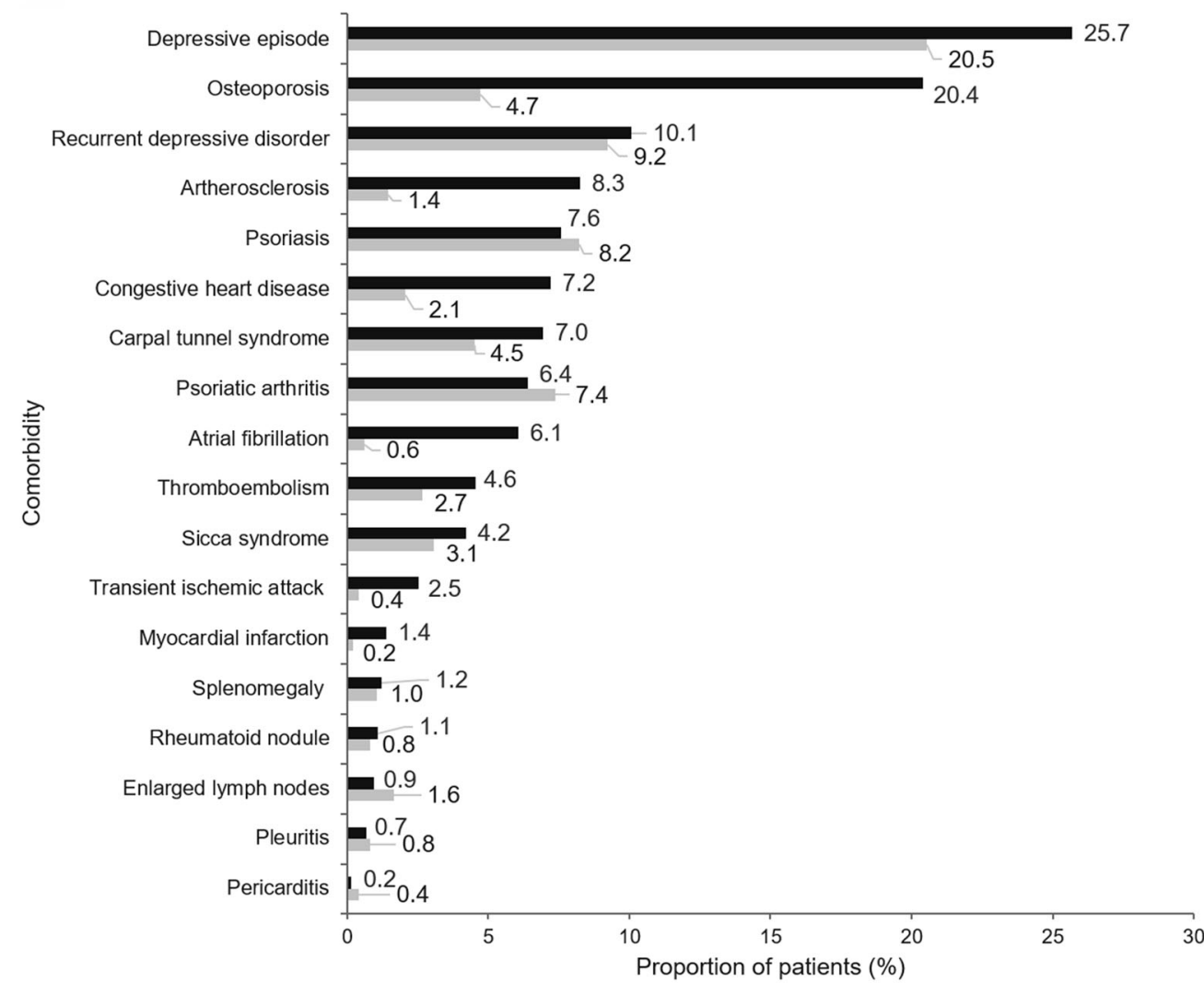

B - Overall $(n=1,737) \backsim$ Women of childbearing age $(n=124)$

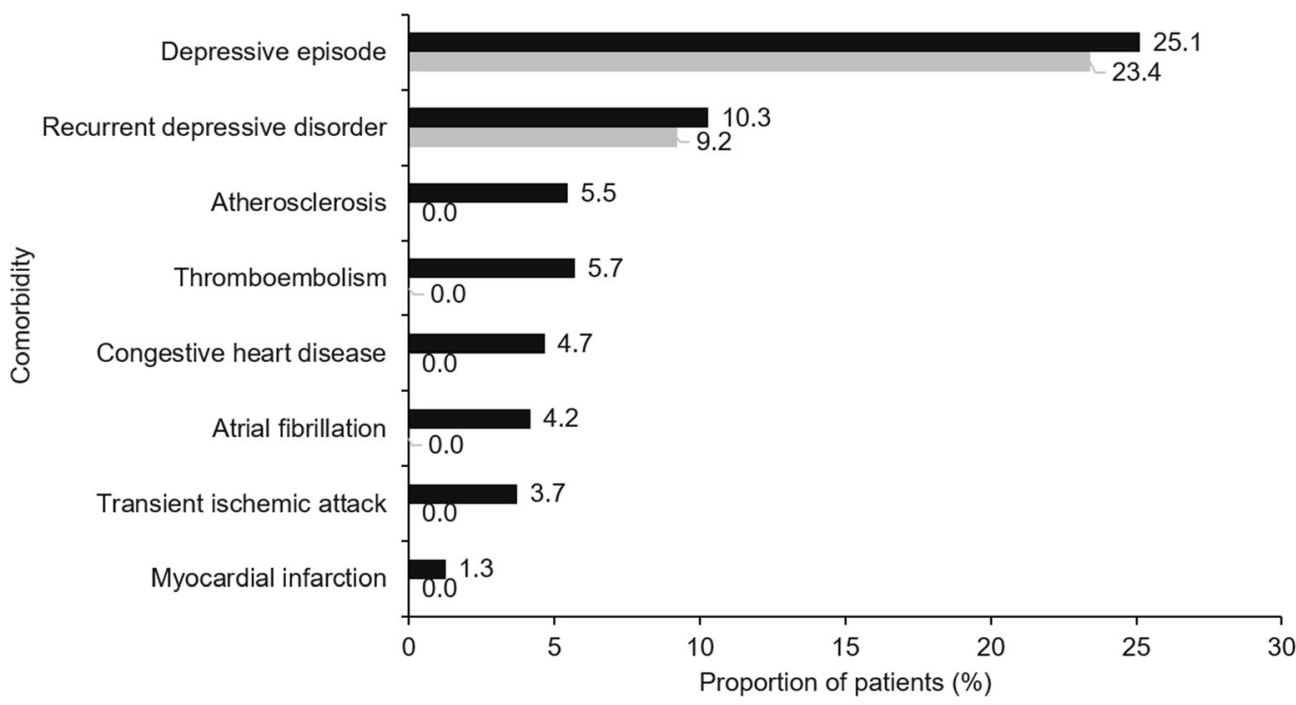

Fig. 3 Frequency of comorbidities of interest. a RA patients. b PsA patients. c PSO patients. Data reported from 2016. PsA psoriatic arthritis, $P S O$ psoriasis, $R A$ rheumatoid arthritis

prescribed anti-TNF therapies by internal medicine specialists (46.2\%) and rheumatologists
(30.8\%), while immunosuppressants were most frequently prescribed by dermatologists (62.4\%) 


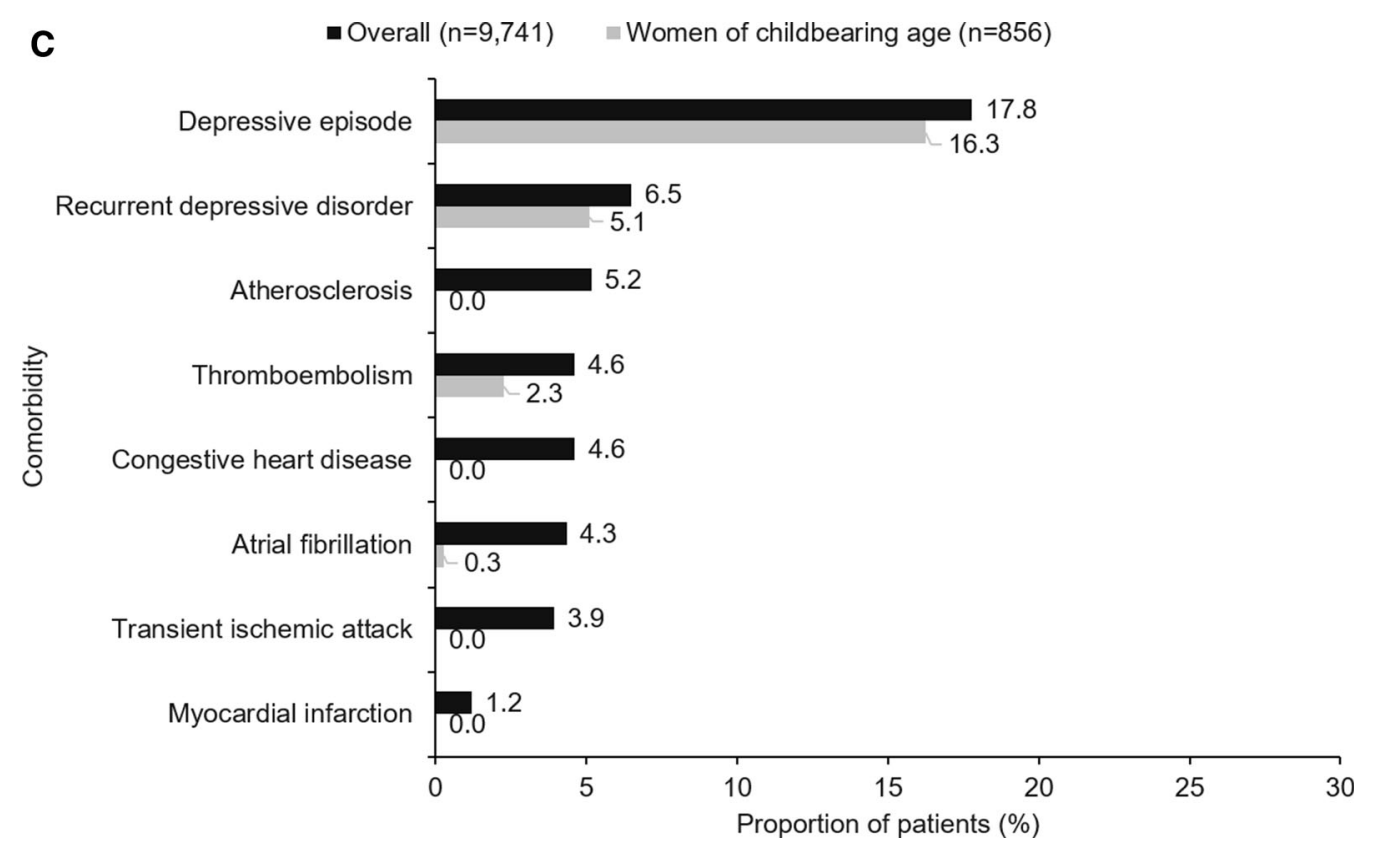

Fig. 3 continued

(Fig. 5c). Few patients with PsA or PSO were prescribed other biologics, and a small number of PsA patients were prescribed anti-TNF bio$\operatorname{logics}$ (Fig. 5b, c).

\section{Treatment Patterns}

\section{Distribution of Treatment}

In $2016,55.3 \%$ of prevalent RA patients were receiving systemic anti-inflammatory treatment (Table S4). In the total RA patient population, $38.3 \%$ received MTX and $10.1 \%$ received leflunomide. The most common anti-TNF biologics in this population were etanercept (4.6\%) and adalimumab (3.5\%) (Fig. 6a), and this was consistent throughout the study period. Among women of childbearing age with RA, 49.7\% were receiving systemic treatment in 2016 (Table S4). There was a notable decrease in the treatment rates for women of childbearing age with RA over the study period (from $57.8 \%$ in 2012 to $49.7 \%$ in 2016). Among women of childbearing age with RA in 2016, the most common csDMARD was MTX which was received by $27.5 \%$ of patients. The most common anti-TNF biologics received by this group were etanercept (5.5\%), adalimumab (5.1\%) and certolizumab pegol (3.7\%) (Fig. 6a).

Less than half of the prevalent patients with PsA (43.9\%) were receiving systemic anti-inflammatory treatment in 2016 (Table S4). In the overall PsA patient population, the most common medications were MTX (30.2\%) and adalimumab (6.8\%) (Fig. 6b). Among women of childbearing age with PsA, 51.9\% were receiving systemic treatment (Table S4). The most common medication among women of childbearing age with PsA was MTX (22.9\%), and the most frequently used biologics were adalimumab (7.6\%), secukinumab (6.1\%) and etanercept (5.8\%) (Fig. 6b).

Among the prevalent PSO patient population, only $4.1 \%$ were reported to be receiving systemic anti-inflammatory treatment in 2016 (Table S4). The most common systemic therapies in the overall PSO patient population were MTX (2.2\%) and fumaric acid (2.0\%) (Fig. 6c). Adalimumab was the most frequently prescribed anti-TNF biologic $(0.6 \%)$. The distribution of treatments was similar for women of childbearing age (Fig. 6c; Table S4). 

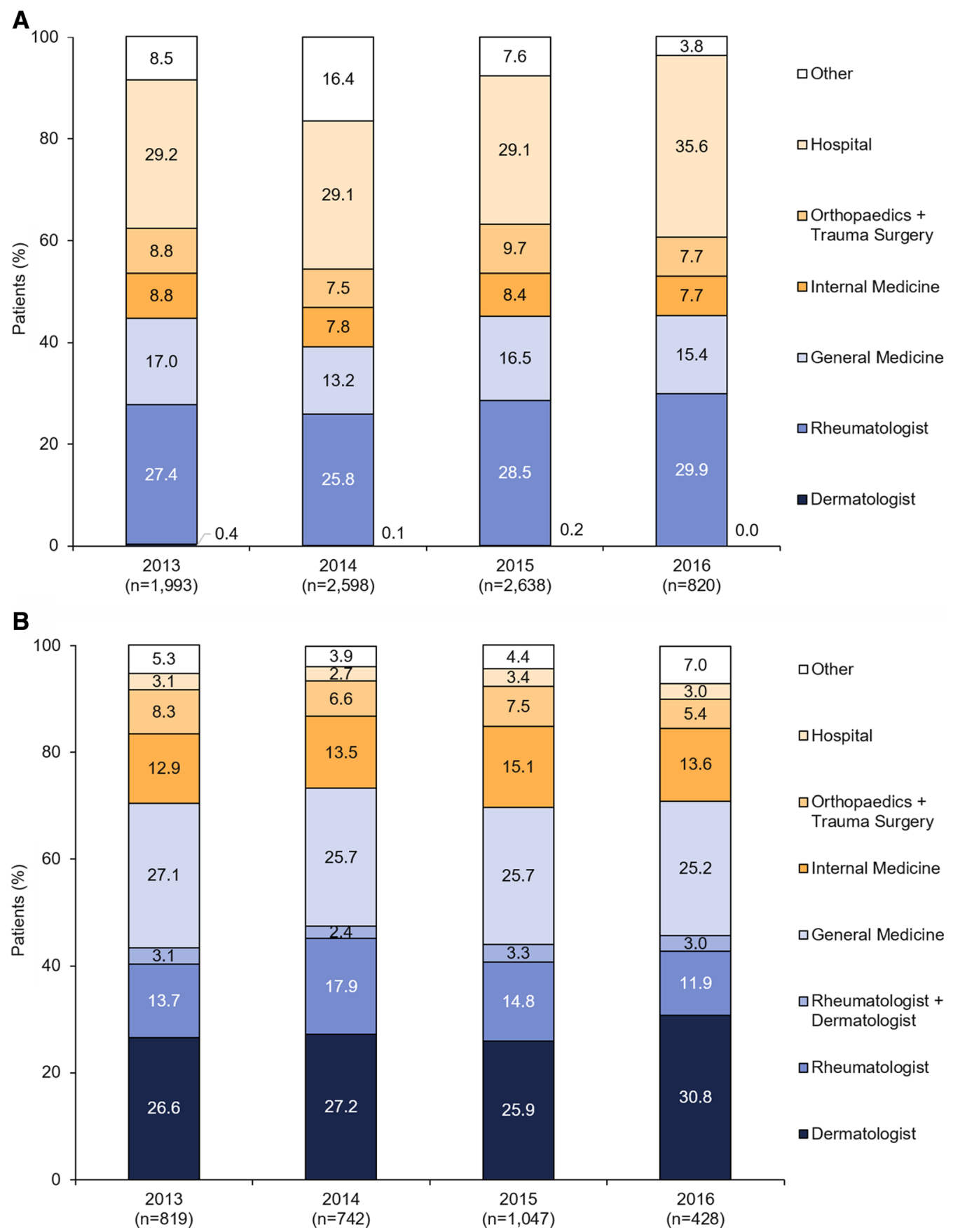

Fig. 4 Diagnosing physicians. a RA patients. b PsA patients. c PSO patients. Data reported from between 2013 and 2016. $P s A$ psoriatic arthritis, $P S O$ psoriasis, $R A$ rheumatoid arthritis

\section{Treatment Lines}

More than half of patients with RA who were treated with adalimumab $(69.8 \%)$, etanercept $(67.4 \%)$, rituximab $(56.6 \%)$ and certolizumab pegol (53.1\%) were biologic-naïve, and of those receiving tocilizumab, 33.0\% received it as their first biologic treatment (Fig. S2a). The majority of PsA and PsO patients treated with adalimumab (PsA: 90.3\%; PSO: 94.3\%) and 


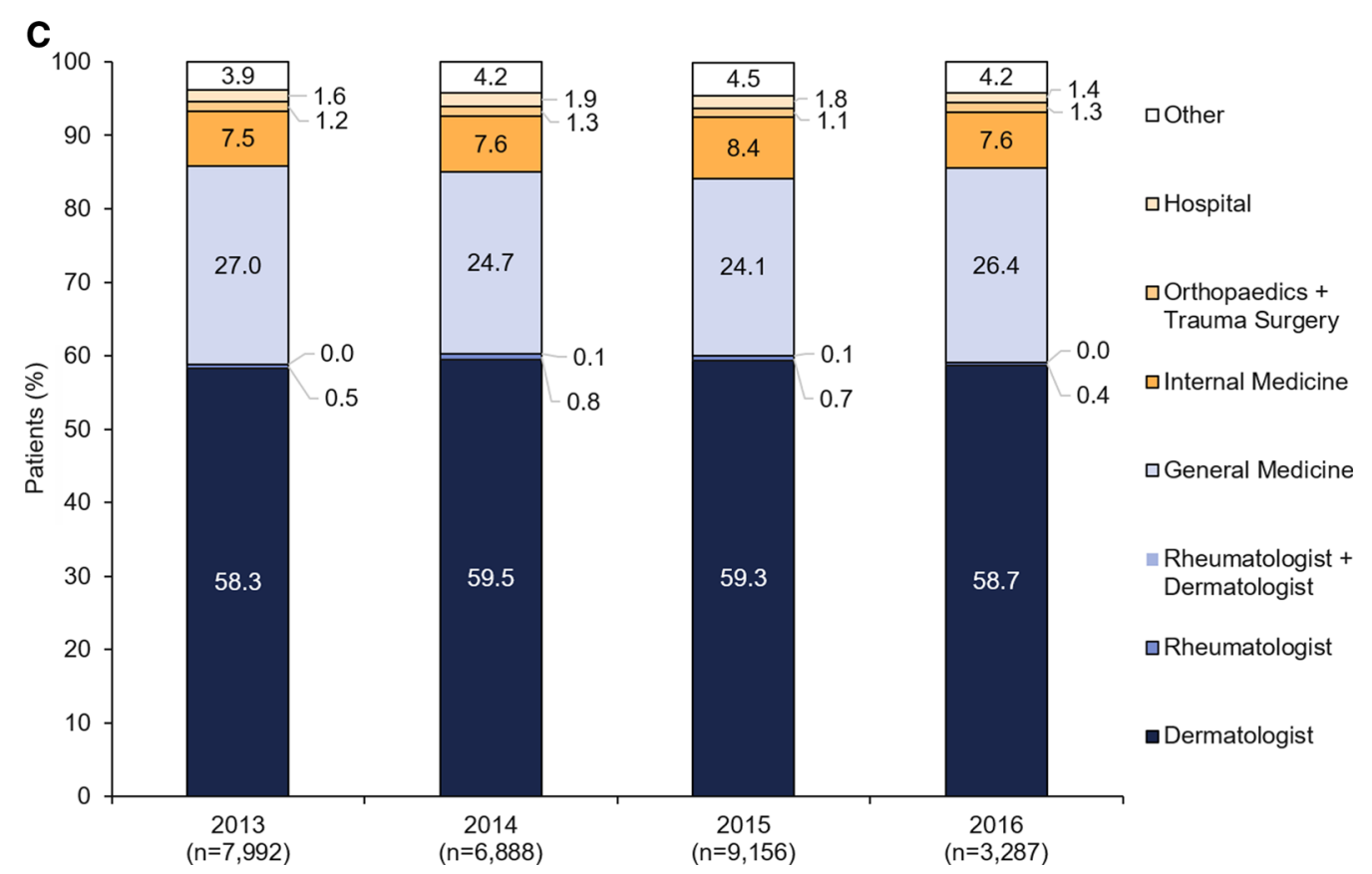

Fig. 4 continued

etanercept (PsA: 86.5\%; PSO: 88.6\%) were biologic-naïve (Fig. S2b, c).

\section{Persistence}

For patients with RA, persistence on treatment was longest for anti-TNF in combination with csDMARD therapy; approximately half of patients remained on therapy after 270 days compared with approximately $30 \%$ of patients receiving an anti-TNF alone (Fig. S3a).

Persistence on treatment was longer for biologic-naïve patients with PsA; roughly 60\% remained on therapy after 270 days compared to $50 \%$ for biologic-experienced patients (Fig. S3b). A similar persistence pattern was observed for patients with PSO (Fig. S3c).

The mean (standard error [SE]) duration on treatment for biologic-naïve patients with RA, PsA and PSO were $288( \pm 12), 232( \pm 5)$ and 245 $( \pm 6)$ days, respectively (Table S5). Average treatment durations were similar for the women of childbearing age subgroup for each indication (Table S5).

\section{Dosing patterns}

More than half of biologic-naïve PSO patients $(53.9 \%)$ received above-label dosing of biologics for a period of at least 30 days, with approximately $12 \%$ receiving high-level dosing ( $\geq 170 \%$ of the recommend dose) (Fig. 7). Data for biologic-experienced PSO patients were also collected but are not reported because of low patient numbers.

\section{DISCUSSION}

This retrospective study of German healthcare insurance data showed that RA, PsA and PSO had prevalence rates of $0.4 \%, 0.3 \%$ and $2.1 \%$, respectively, in 2016 in Germany. All three indications were prevalent across all age groups, but were most common in patients $>45$ years of age. While PSO had an approximately equal gender distribution, RA and PsA were more prevalent in women. The patient demographics also showed that women of childbearing age represented a larger proportion of patients with PSO than RA and PsA (in 2016; RA: 12.4\%; PsA: 13.2\%; PSO: $17.7 \%$ ). Comorbid depression was 


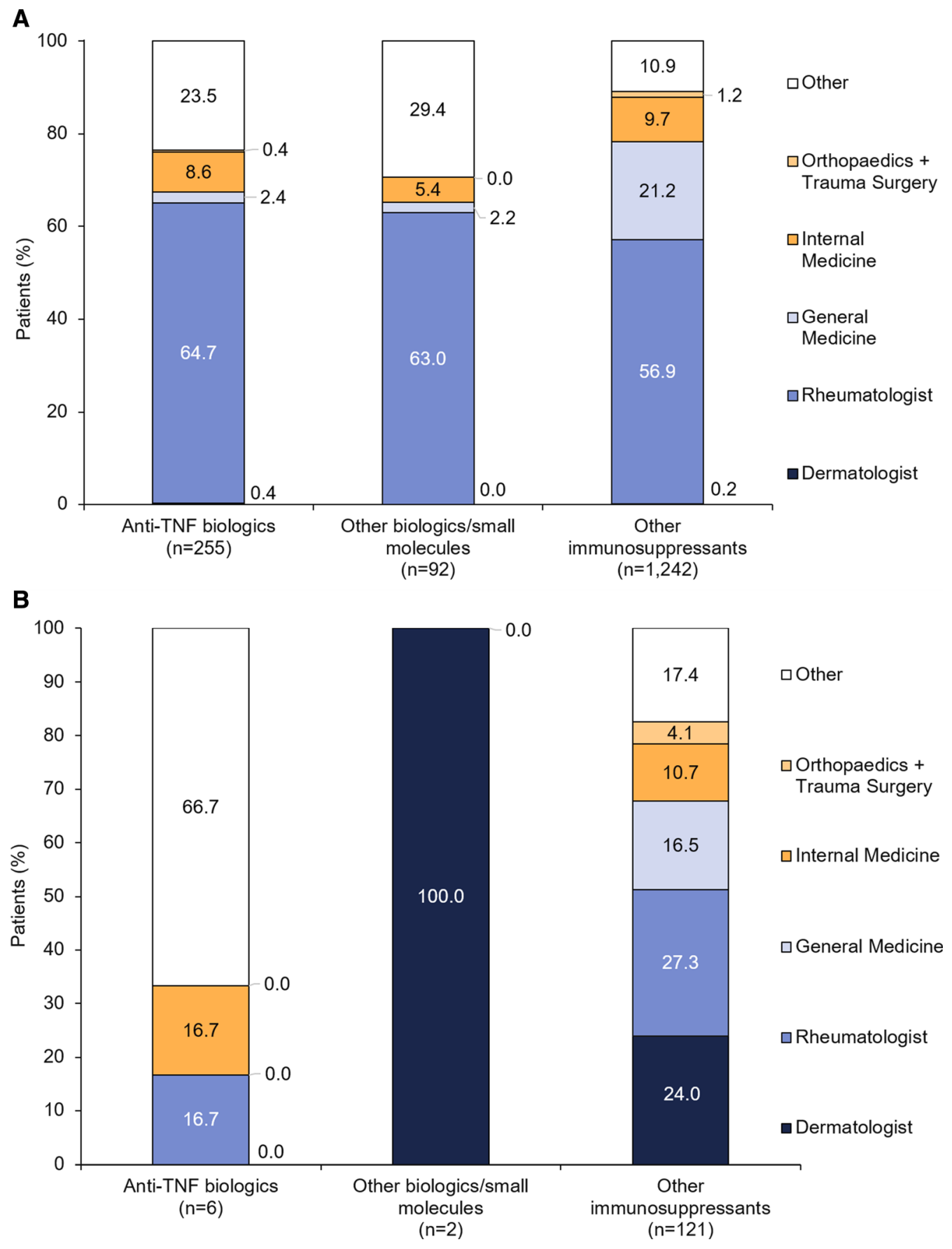

Fig. 5 Treating physicians. a RA patients. b PsA patients. c PSO patients. Treatment classes: anti-TNF biologics (RA: adalimumab, certolizumab pegol, etanercept, infliximab, and golimumab, PsA: adalimumab, certolizumab pegol, etanercept, infliximab, and golimumab, PSO: adalimumab, etanercept, and infliximab); other biologics/small molecules (RA: abatacept, rituximab, and tocilizumab, PsA: apremilast and ustekinumab, PSO: apremilast, secukinumab and ustekinumab); other immunosuppressants (RA: leflunomide, MTX, and sulfasalazine, PsA: acitretin, ciclosporin, fumaric acid, leflunomide, MTX, and sulfasalazine, PSO: acitretin, ciclosporin, fumaric acid, and MTX). Anti-TNF anti-tumour necrosis factor, MTX methotrexate, $P s A$ psoriatic arthritis, $P S O$ psoriasis, $R A$ rheumatoid arthritis 


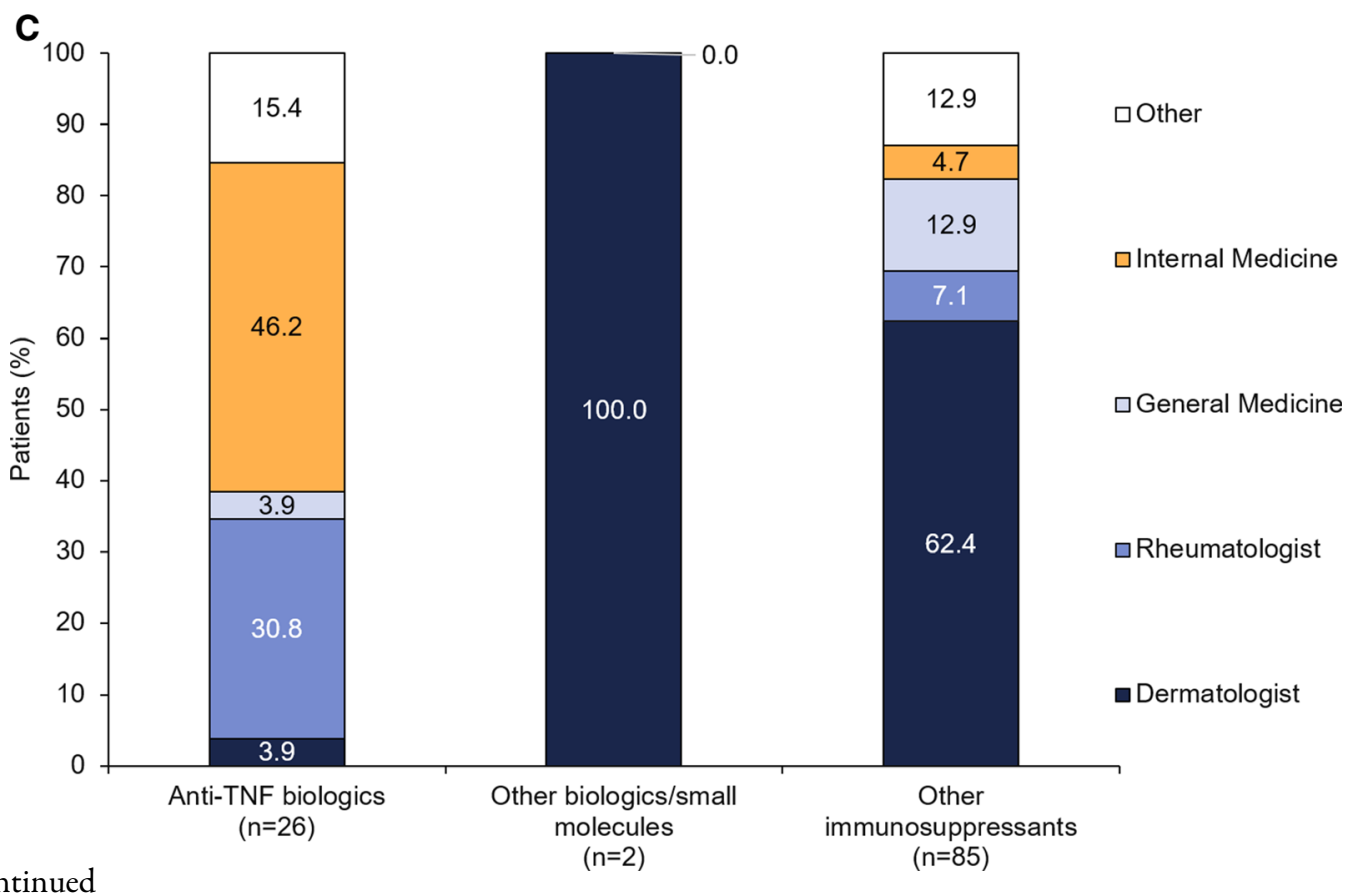

Fig. 5 continued

observed in a large proportion of the patients across all indications. Many patients were not receiving systemic treatment, with only a small number of patients reported to have received treatment with bDMARDs.

The observed prevalence rates for RA were lower than reported in the literature, which could be explained by differing classification and/or misdiagnosis of RA [1]. Results from the PROCLAIR (linking Patient-Reported Outcomes with CLAims data for health services research In Rheumatology) collaborative project, which focused on claims data for German patients with statutory health insurances, also estimated the prevalence of RA in Germany to be higher than observed here $(0.8-1.0 \%)$, and this is likely attributed to a wider definition of RA being used in the PROCLAIR study [23]. The observed prevalence rates for PsA and PSO were in line with a previous report in the literature [6].

The overall RA patient population was found to experience comorbid osteoporosis to a high extent, but this was less pronounced amongst the women of childbearing age subgroup; a likely explanation for this is that the overall RA population was older (females aged 70-79 years: 1.4\%; males aged $75-84$ years: $0.7 \%$ ) since the prevalence of osteoporosis increases with age
[24] and is most common $>50$ years of age [25]. Furthermore, patients with RA often experience high corticosteroid use, which has been proven to lead to bone loss and is likely a contributing factor to the high level of comorbid osteoporosis observed [26].

Depression was a common comorbidity among RA, PsA and PSO patients, highlighting the mental burden experienced by patients with these disorders. In this retrospective study, depression and recurrent depressive disorder were noted in a higher proportion of patients with RA and PsA compared with patients diagnosed with PSO, but this observation seems to be unsupported in the literature at present. Varying degrees of depression in patients with RA have been reported in the literature; one report showed that $15 \%$ of patients with RA suffered from a comorbid depressive disorder $(n=163)$ [27], and another that $42 \%$ of patients $(n=82)$ were affected [28]. Furthermore, concomitant depression was found to be associated with worsened patient outcomes [29]. Similarly, the PROCLAIR study reported comorbid depression in $52 \%$ of patients with RA $(n=3140)$ [30]. An increased risk of depression, anxiety and suicidality (including suicidal ideation, suicidal attempt[s] and suicide) has 
A

- Overall $(n=2,171) \quad$ Women of childbearing age $(n=242)$

Non-biologics:

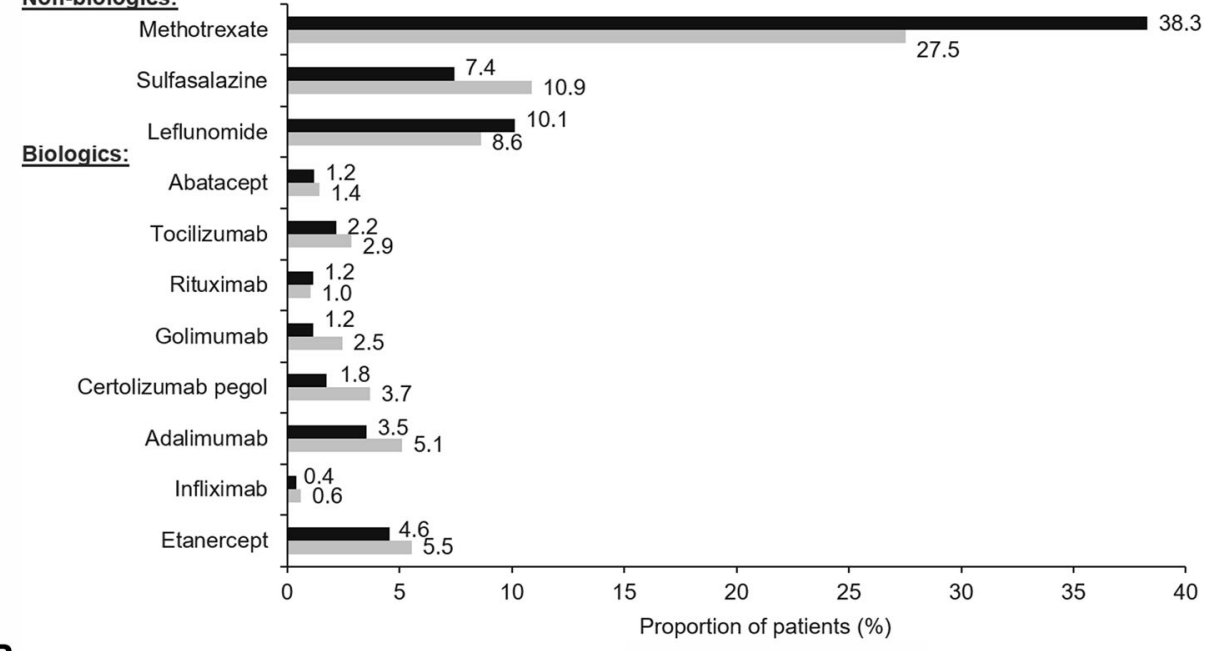

B

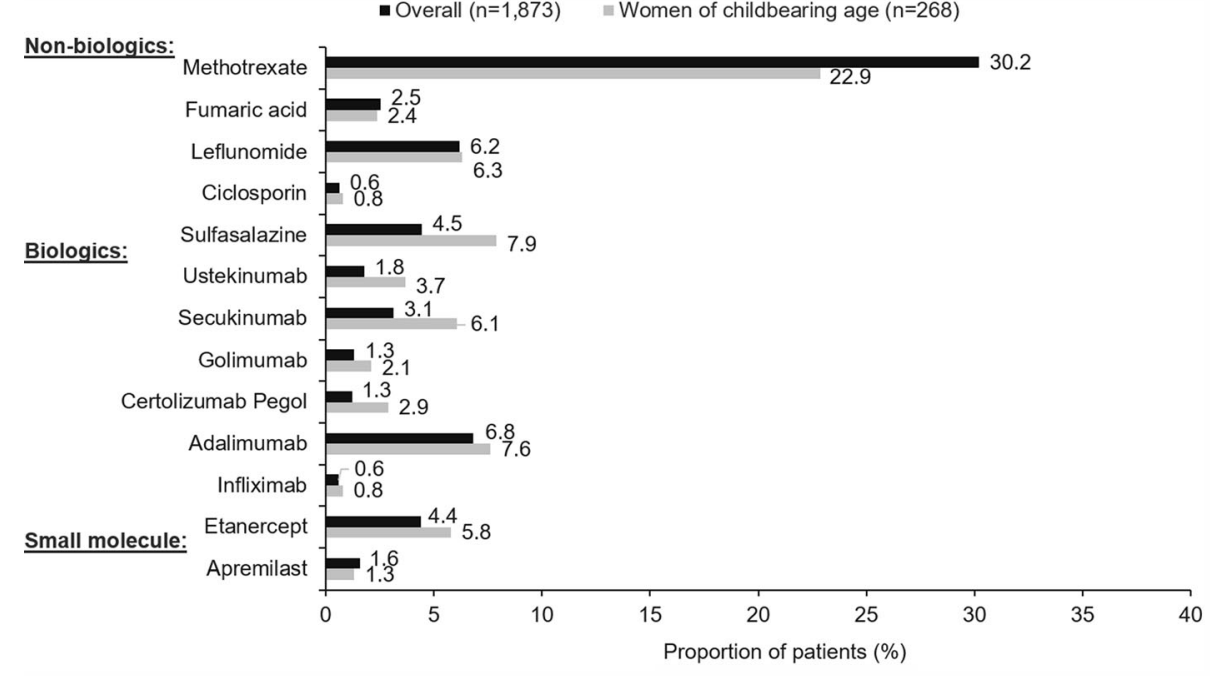

C

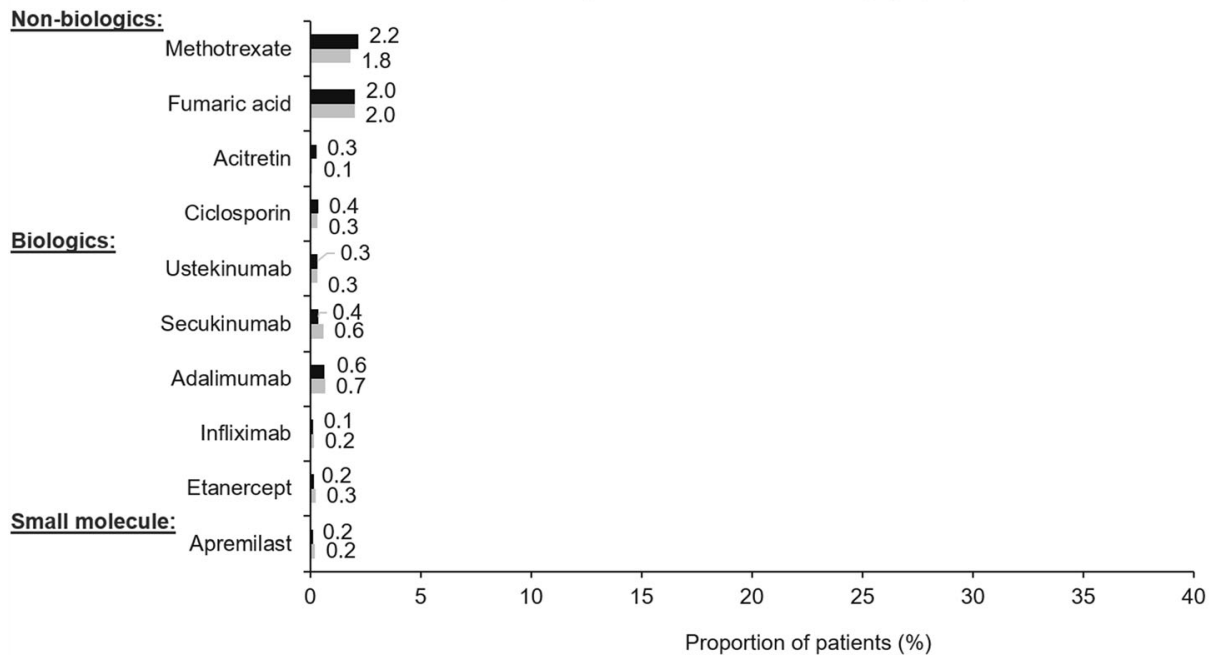


4Fig. 6 Treatment distribution among the overall patient population. a RA patients (overall $n=2171$; women of childbearing age $n=242$ ). b PsA patients (overall $n=2877$; women of childbearing age $n=380$ ). c PSO patients (overall $n=20,240$; women of childbearing age $n=3374$ ). Data were analysed for prevalent patients holding full health cover in 2016. The sum of the percentages is more than the percentage receiving systemic treatment as patients receiving $>1$ treatment were counted multiple times. Ps $A$ psoriatic arthritis, PSO psoriasis, $R A$ rheumatoid arthritis

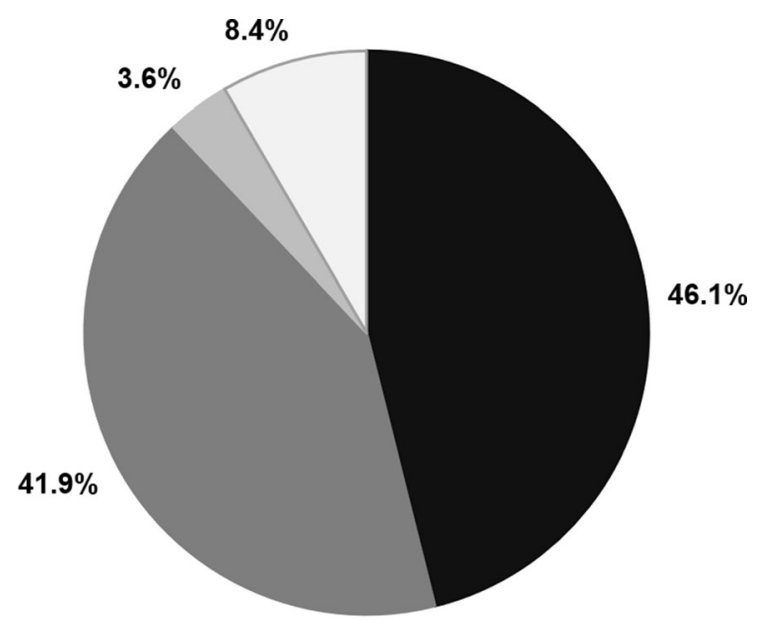

Normal $\quad>100 \%<170 \% \quad \geq 170 \%<200 \% \quad \square \geq 200 \%$

Fig. 7 Proportion of biologic-naivve PSO patients $(n=167)$ receiving first-line biologic therapy in normal versus high-level doses. High-level dosing was defined as $\geq 170 \%$ or $\geq 200 \%$ of a single dose and was required for a period of at least 30 days; patients receiving $\geq 170 \%$ dosing for $<30$ days were assigned to the single dosing group. Data were also collected for biologic-experienced patients but are not reported because of low patient numbers $(n=18)$. PSO psoriasis

also been highlighted in several recent reports for PsA and PSO patients [31, 32].

The observation that only a small proportion of patients with RA and PsA received their diagnosis by a rheumatologist suggests that specialist consultation is uncommon at the first point of physician contact. This is supported by a recent report for RA patients that highlighted that the mean duration from first disease symptom to rheumatologist consultation was
9.2 months, while the mean time to RA diagnosis was 14.2 months [33]. A similar study found that a delay in PsA diagnosis was greater than one year in nearly half of the patients [34]. The majority of patients with RA received treatment prescribed by a rheumatologist but treatment initiation was also found to be delayed (mean duration from first disease symptom of 16.9 months) [33]. Amongst patients with PSO, the majority receive their diagnosis and treatment by a dermatologist. Delays in treatment initiation seem to be unsupported in the literature for patients with PSO.

The differing classification and/or misdiagnosis of RA described above could be one of the main reasons for the observation that only half of the patients with RA in this study were receiving systemic treatment [1]. Furthermore, the severity of the RA among patients in this study population was not known. The observation in the present study that $29.2 \%$ of patients with PsA also had comorbid RA suggests that treatment may also be complicated by the fact that some patients do not have a single, clear diagnosis. Delayed diagnosis and treatment initiation have also been highlighted for patients with RA, which may be another reason for the large proportion of patients not receiving treatment [33]. The observation that many patients diagnosed with PsA and PSO were not receiving any systemic treatment is supported by a population-based multinational assessment survey for patients with PsA and PSO conducted in 2012 [3]. In this survey, $59.0 \%$ of PsA patients reported they were receiving no treatment or only topical therapy, and for patients with PSO, 5.0\% were reported receiving conventional DMARDs and 3.0\% were receiving biologic therapy [3]. For patients with PSO it is interesting that while the majority of patients are not treated systemically, among those that are treated with a biologic more than half received above-label dosing (53.9\%). Delayed PsA diagnosis, which was highlighted in a recent report [34], is likely a contributing factor to patients not receiving treatment.

MTX was the most common DMARD prescribed to patients across all the reported disease areas. Since the approved treatment guidelines 
for RA [10, 35, 36] and PsA [37-39] that were in place from 2012 to 2016 state that MTX is the recommended first therapy, this observation is reasonable. bDMARDs were prescribed much less frequently to patients across all indications. In this study, etanercept was the most frequently prescribed anti-TNF therapy for patients with RA, while adalimumab was the most frequently prescribed anti-TNF for PsA and PSO patients. Certolizumab pegol was prescribed for patients with RA and PsA but was not approved for treatment of PSO at the time of this study. Since the severity of disease for the patients in this study is unknown, this could be a contributing factor to the minimal number of patients receiving bDMARDs. Recent treatment guidelines for RA [11, 40], PsA [12] and PSO [41] all suggest bDMARDs should be used where patients have more severe disease progression and insufficient response to csDMARDs.

Data from the EXXELERATE study, a 2-year head-to-head comparison between certolizumab pegol + MTX and adalimumab + MTX in patients with RA, demonstrated that switching to another antiTNF in the event of inadequate response has clinical benefit [42]. In a retrospective cohort study conducted in Germany using the Electronic Medical Record database of the IMS Disease Analyzer, which analysed treatment persistence for patients with RA and PsA patients initiating subcutaneous biologic therapies with and without prior use of DMARDs, the percentages of RA and PsA patients persistent $\geq 12$ months were $51.9 \%(n=576)$ and $57.9 \% \quad(n=197)$, respectively [43], which is similar to the observations in this study. Average treatment durations observed (246 days for RA and 264 days for PsA) were also in line with what was reported for patients in this study [43]. Furthermore, in patients with RA, persistence on treatment was shown to be higher for DMARD-experienced patients [43]. In contrast, no significant difference in persistence was observed between DMARD-naïve and DMARDexperienced PsA patients [43]. Another German claims database study including patients with a PSO diagnosis showed that overall 12-month persistence on treatment was $56 \%(n=347)$ in a mixed cohort of biologic-naïve and experienced patients, which supports our findings [44].

A limitation of this study was the inability in infer causality because of the cross-sectional analyses that were performed to observe demographics, epidemiology, comorbidities and diagnosing physicians. Furthermore, it is important to note that real-world studies can be prone to bias because of the inability to control data collection and that changes over time in medical practice and disease biology were not captured in this study [45]. This study was also limited by the potential for misdiagnoses, observed overlap between diagnoses and missing or incomplete patient records, which is common to all database studies and could lead to underestimation of disease prevalence. Patients $<18$ years old and those without insurance were also excluded from the study, making the sample slightly less representative of the entire population. Despite these limitations, retrospective database studies are important as they include large representative patient populations and can provide insights beyond those obtained from randomised controlled trials [45].

\section{CONCLUSIONS}

In conclusion, this analysis provides key epidemiological information for patients with RA, PsA and PSO in terms of prevalence and incidence rates and demographics for physicians and further highlights common comorbidities and treatment patterns. For patients with RA, concomitant csDMARDs alongside anti-TNF treatments resulted in greater treatment persistence. However, many of these German patients with RA, PsA and PSO were not receiving any systemic treatment, indicating that these patients may be undertreated for their diagnoses. In addition, frequent comorbid depression highlights the mental burden experienced by patients diagnosed with RA, PsA and PSO. Real-world studies like this are of great importance to understanding comorbidities and treatment patterns in order to propose solutions to improve patient outcomes. 


\section{ACKNOWLEDGEMENTS}

The authors acknowledge Fredrik Fierens, PhD, UCB Pharma, Brussels, Belgium, for publication coordination.

Funding. This study, the Rapid Service and Open Access fees were funded by UCB Pharma.

Medical Writing Assistance. The authors acknowledge Beverley Wilson, PhD, Costello Medical, Manchester, UK, and Sarah Jayne Clements, PhD, Costello Medical, Cambridge, UK, for medical writing and editorial assistance in preparing this manuscript, based on the authors' input and direction. This was funded by UCB Pharma in accordance with Good Publication Practice (GPP3) guidelines (https:// www.ismpp.org/gpp3).

Authorship. All named authors meet the International Committee of Medical Journal Editors (ICMJE) criteria for authorship for this article, take responsibility for the integrity of the work as a whole, and have given their approval for this version to be published.

Authorship Contributions. Substantial contributions to study conception and design: CG, WD, VF, RS, AS, LJ; Substantial contributions to acquisition of data: CG, WD, VF, RS, AS, LJ; Substantial contributions to analysis and interpretation of data: CG, WD, VF, RS, AS, LJ; Drafting the article or revising it critically for important intellectual content: CG, WD, VF, RS, AS, LJ; Final approval of the version of the article to be published: CG, WD, VF, RS, AS, LJ.

Disclosures. Claudia Grellmann has nothing to disclose. Wojciech Dombrowsky, Volker Fabricius, Robert Suruki, Anna Sheahan and Lars Joeres are employees of UCB Pharma.

Compliance with Ethics Guidelines. Ethical approval was not required for this study as the data analysed were retrospective and were pseudonymised and anonymised, so that the subsequent assignment to patient data was impossible. Permission to use the database was provided by Arvato Health Analytics, the former operators of the database.

Data Availability. Data from non-clinical studies are outside of UCB's data sharing policy.

Open Access. This article is licensed under a Creative Commons Attribution-NonCommercial 4.0 International License, which permits any non-commercial use, sharing, adaptation, distribution and reproduction in any medium or format, as long as you give appropriate credit to the original author(s) and the source, provide a link to the Creative Commons licence, and indicate if changes were made. The images or other third party material in this article are included in the article's Creative Commons licence, unless indicated otherwise in a credit line to the material. If material is not included in the article's Creative Commons licence and your intended use is not permitted by statutory regulation or exceeds the permitted use, you will need to obtain permission directly from the copyright holder. To view a copy of this licence, visit http:// creativecommons.org/licenses/by-nc/4.0/.

\section{REFERENCES}

1. Fuchs J, Rabenberg M, Scheidt-Nave C. Prevalence of selected musculoskeletal conditions in Germany: results of the German health interview and examination survey for adults (DEGS1). Bundesgesundheitsblatt Gesundheitsforschung Gesundheitssc hutz. 2013;56(5-6):678-86.

2. Mease PJ, Armstrong AW. Managing patients with psoriatic disease: the diagnosis and pharmacologic treatment of psoriatic arthritis in patients with psoriasis. Drugs. 2014;74(4):423-41.

3. Kavanaugh A, Helliwell P, Ritchlin CT. Psoriatic arthritis and burden of disease: patient perspectives from the population-based multinational assessment of psoriasis and psoriatic arthritis (MAPP) survey. Rheumatol Ther. 2016;3(1):91-102.

4. Gladman DD, Antoni C, Mease P, Clegg DO, Nash P. Psoriatic arthritis: epidemiology, clinical features, course, and outcome. Ann Rheum Dis. 2005;64(Suppl 2):ii14-ii17. 
5. Gottlieb A, Korman NJ, Gordon KB, et al. Guidelines of care for the management of psoriasis and psoriatic arthritis: Section 2 Psoriatic arthritis: overview and guidelines of care for treatment with an emphasis on the biologics. J Am Acad Dermatol. 2008;58(5):851-64.

6. Augustin M, Reich K, Glaeske G, Schaefer I, Radtke M. Co-morbidity and age-related prevalence of psoriasis: analysis of health insurance data in Germany. Acta Derm Venereol. 2010;90(2):147-51.

7. World Health Organisation. Global report on psoriasis 2016 [cited March 2020]. https://apps.who. int/iris/handle/10665/204417. Accessed Mar 2020.

8. Sewerin P, Brinks R, Schneider M. Prevalence and incidence of psoriasis and psoriatic arthritis. Ann Rheum Dis. 2019;78:286-7.

9. Doria A, Zavaglia D. Monotherapy is a relevant option in rheumatoid arthritis treatment: a literature review. Clin Exp Rheumatol. 2019. (epub ahead of print).

10. Wollenhaupt J, Albrecht K, Kruger K, Muller-Ladner U. The new 2012 German recommendations for treating rheumatoid arthritis: differences compared to the European standpoint. Z Rheumatol. 2013;72(1):6-9.

11. Smolen JS, Landewé RBM, Bijlsma JWJ, et al. EULAR recommendations for the management of rheumatoid arthritis with synthetic and biological disease-modifying antirheumatic drugs: 2019 update. Ann Rheum Dis. 2020;79(6):685-99.

12. Gossec L, Baraliakos X, Kerschbaumer A, et al. EULAR recommendations for the management of psoriatic arthritis with pharmacological therapies: 2019 update. Ann Rheum Dis. 2020;79(6):700-12.

13. Ritchlin CT, Kavanaugh A, Gladman DD, et al. Treatment recommendations for psoriatic arthritis. Ann Rheum Dis. 2009;68(9):1387-94.

14. Nast A, Kopp I, Augustin M, et al. German evidencebased guidelines for the treatment of psoriasis vulgaris (short version). Arch Dermatol Res. 2007;299(3):111-38.

15. Sherman RE, Anderson SA, Dal Pan GJ, et al. Realworld evidence-what is it and what can it tell us? N Engl J Med. 2016;375(23):2293-7.

16. Yuan H, Ali MS, Brouwer ES, et al. Real-world evidence: what it is and what it can tell us according to the International Society for Pharmacoepidemiology (ISPE) Comparative Effectiveness Research (CER) Special Interest Group (SIG). Clin Pharmacol Ther. 2018;104(2):239-41.
17. Gossen N, Jacob L, Kostev K. Second-line therapy with biological drugs in rheumatoid arthritis patients in German rheumatologist practices: a retrospective database analysis. Rheumatol Int. 2016;36(8):1113-8.

18. van de Kerkhof PC, Reich K, Kavanaugh A, et al. Physician perspectives in the management of psoriasis and psoriatic arthritis: results from the population-based Multinational Assessment of Psoriasis and Psoriatic Arthritis survey. J Eur Acad Dermatol Venereol. 2015;29(10):2002-100.

19. Griffiths CEM, Jo SJ, Naldi L, et al. A multidimensional assessment of the burden of psoriasis: results from a multinational dermatologist and patient survey. Br J Dermatol. 2018;179(1):173-81.

20. Lin PT, Wang SH, Chi CC. Drug survival of biologics in treating psoriasis: a meta-analysis of realworld evidence. Sci Rep. 2018;8(1):16068.

21. Barker J, Girolomoni G, Egeberg A, Goncalves J, Pieper B, Kang T. Anti-TNF biosimilars in psoriasis: from scientific evidence to real-world experience. J Dermatol Treat. 2020;31(8):794-800.

22. Griffiths CEM, Augustin $M$, Naldi $L$, et al. Patient-dermatologist agreement in psoriasis severity, symptoms and satisfaction: results from a real-world multinational survey. J Eur Acad Dermatol Venereol. 2018;32(9):1523-9.

23. Callhoff J, Albrecht K, Hoffmann F, Poddubnyy D, Gunther KP, Zink A. Reality of care for musculoskeletal diseases at the population level: results of the PROCLAIR collaborative project. Z Rheumatol. 2019;78(Suppl 2):73-9.

24. Hernlund E, Svedbom A, Ivergard M, et al. Osteoporosis in the European Union: medical management, epidemiology and economic burden. A report prepared in collaboration with the International Osteoporosis Foundation (IOF) and the European Federation of Pharmaceutical Industry Associations (EFPIA). Arch Osteoporos. 2013;8:136.

25. International Osteoporosis Foundation. Broken bones, broken lives: a roadmap to solve the fragility fracture crisis in Europe [cited March 2020]. https:// share.iofbonehealth.org/EU-6-Material/Reports/ IOF\%2520Report_EU.pdf. Accessed Mar 2020.

26. Briot K, Roux C. Corticosteroid-induced osteoporosis. Rev Med Interne. 2013;34(5):315-23.

27. Pincus T, Griffith J, Pearce S, Isenberg D. Prevalence of self-reported depression in patients with rheumatoid arthritis. Br J Rheumatol. 1996;35(9): 879-83. 
28. Isik A, Koca SS, Ozturk A, Mermi O. Anxiety and depression in patients with rheumatoid arthritis. Clin Rheumatol. 2007;26(6):872-8.

29. Margaretten M, Julian L, Katz P, Yelin E. Depression in patients with rheumatoid arthritis: description, causes and mechanisms. Int J Clin Rheumtol. 2011;6(6):617-23.

30. Jobski K, Luque Ramos A, Albrecht K, Hoffmann F. Pain, depressive symptoms and medication in German patients with rheumatoid arthritis-results from the linking patient-reported outcomes with claims data for health services research in rheumatology (PROCLAIR) study. Pharmacoepidemiol Drug Saf. 2017;26(7):766-74.

31. Kurd SK, Troxel AB, Crits-Christophe P, Gelfand JM. The risk of depression, anxiety, and suicidality in patients with psoriasis. Arch Dermatol. 2010;146(8):891-5.

32. McDonough E, Ayearst R, Eder L, et al. Depression and anxiety in psoriatic disease: prevalence and associated factors. J Rheumatol. 2014;41:887-96.

33. Rosa JE, García MV, Luissi A, et al. Rheumatoid arthritis patient's journey: delay in diagnosis and treatment. J Clin Rheumatol. 2020;26(7S Suppl 2): S148-52.

34. Moyano S, Brom M, Mollerach F, et al. AB0789 The psoriatic arthritis patient's journey: special emphasis on diagnosis and treatment delays. Ann Rheum Dis. 2017;76(Suppl 2):1333.

35. Smolen JS, Landewé R, Breedveld FC, et al. EULAR recommendations for the management of rheumatoid arthritis with synthetic and biological disease-modifying antirheumatic drugs: 2013 update. Ann Rheum Dis. 2014;73(3):492-509.

36. Smolen JS, Landewé R, Breedveld FC, et al. EULAR recommendations for the management of rheumatoid arthritis with synthetic and biological disease-modifying antirheumatic drugs. Ann Rheum Dis. 2010;69(6):964-75.
37. Gossec L, Coates LC, de Wit M, et al. Management of psoriatic arthritis in 2016: a comparison of EULAR and GRAPPA recommendations. Nat Rev Rheumatol. 2016;12(12):743-50.

38. Gossec L, Smolen JS, Gaujoux-Viala C, et al. European League Against Rheumatism recommendations for the management of psoriatic arthritis with pharmacological therapies. Ann Rheum Dis. 2012;71(1):4-12.

39. Gossec L, Smolen JS, Ramiro S, et al. European League Against Rheumatism (EULAR) recommendations for the management of psoriatic arthritis with pharmacological therapies: 2015 update. Ann Rheum Dis. 2016;75(3):499-510.

40. Mian A, Ibrahim F, Scott DL. A systematic review of guidelines for managing rheumatoid arthritis. BMC Rheumatol. 2019;3:42.

41. Wcislo-Dziadecka D, Zbiciak-Nylec M, BrzezinskaWcislo L, Mazurek U. TNF-alpha in a molecularly targeted therapy of psoriasis and psoriatic arthritis. Postgrad Med J. 2016;92(1085):172-8.

42. Smolen JS, Burmester G-R, Combe B, et al. Head-tohead comparison of certolizumab pegol versus adalimumab in rheumatoid arthritis: 2-year efficacy and safety results from the randomised EXXELERATE study. Lancet. 2016;388(10061):2763-74.

43. Lyu R, Govoni M, Ding Q, et al. Treatment persistence among patients with rheumatoid disease (RA, AS, PsA) treated with subcutaneous biologics in Germany. Rheumatol Int. 2016;36(1):143-53.

44. Mahlich J, Alba A, Hadad LE, Leisten M-K, Peitsch WK. Drug survival of biological therapies for psoriasis treatment in germany and associated costs: a retrospective claims database analysis. Adv Ther. 2019;36(7):1684-99.

45. Camm AJ, Fox KAA. Strengths and weaknesses of 'real-world' studies involving non-vitamin K antagonist oral anticoagulants. Open Heart. 2018;5(1):e000788. 